\title{
Analysis of Coal Swelling Deformation Caused by Carbon Dioxide Adsorption Based on X-Ray Computed Tomography
}

\author{
Xiangrong Nie $\mathbb{D}^{1,2}$ Junbin Chen, ${ }^{1,2}$ Yi Cao, ${ }^{1,2}$ Diguang Gong, ${ }^{1,2}$ and Hao Deng ${ }^{1}$ \\ ${ }^{1}$ College of Petroleum Engineering, Xi'an Shiyou University, Xi'an 710065, China \\ ${ }^{2}$ Shaanxi Key Laboratory of Well Stability and Fluid \& Rock Mechanics in Oil and Gas Reservoirs, Xi'an Shiyou University, \\ Xi'an 710065, China
}

Correspondence should be addressed to Xiangrong Nie; nxrcup@163.com

Received 3 May 2018; Revised 10 July 2018; Accepted 1 August 2018; Published 16 September 2018

Academic Editor: Umberta Tinivella

Copyright (C) 2018 Xiangrong Nie et al. This is an open access article distributed under the Creative Commons Attribution License, which permits unrestricted use, distribution, and reproduction in any medium, provided the original work is properly cited.

The geologic sequestration of carbon dioxide by coal beds leads to the swelling deformation of coal. In order to investigate the swelling deformation characteristics at the microscopic scale, X-ray computed tomography (CT) scanning technology was used. $\mathrm{X}$-ray CT scanning technology detects the internal structure, deformation, and porosity of coal at different gas pressures. Results show that swelling deformation is nonuniform, which is caused by the heterogeneity of the coal structure. Through quantitative measurement of the distance between fractures and pseudocolor processing of CT images, we observed that fractures gradually close with the increase of adsorption pressure. As adsorption pressure increases, the porosity of coal decreases, and the density of coal increases.

\section{Introduction}

The geologic storage of carbon dioxide $\left(\mathrm{CO}_{2}\right)$ is expected to be an effective tool to reduce carbon emissions [1]. Coal beds may provide a geological storage $\mathrm{CO}_{2} \cdot \mathrm{CO}_{2}$ injected into coal beds enhances coal bed methane (CBM), taking advantage of competitive adsorption. $\mathrm{CO}_{2}$ geological storage-enhanced coal bed methane recovery $\left(\mathrm{CO}_{2}\right.$-ECBM) is a new technology that has been proposed to implement $\mathrm{CO}_{2}$ storage in coal beds and also enhance the recovery of $\mathrm{CBM}[2,3]$. However, the injection capacity and storage potential of $\mathrm{CO}_{2}$ in coal beds will decrease as a result of coal swelling deformation [4-6]. Thus, it is necessary to study the coal swelling deformation caused by $\mathrm{CO}_{2}$.

Multiple studies have been performed examining coal swelling deformation be divided into direct methods and indirect methods. Direct methods include the dilatometer, the stress meter, and the optical. Briggs and Sinha [7], Reucroft and Patel, Reucroft and Sethuraman $[8,9]$, and Walker et al. [10] used the dilatometer method, which involves placing a probe at the top of a coal sample, to study the volumetric strain of lignite, subbituminous coal, and bituminous coal. Moffat and Weale [11], Harpalani and Schraufnagel [12], Levine [13], St. George and Barakat [14], Cui et al. [15], Majewska and Zietek [16], and Zarebska and Ceglarska-Stefanska [17] used the stress meter to measure the volumetric strain of coal samples. The stress method is a common method that monitors the change in sample length by placing a stress meter on the surface of a sample. Recent studies have utilized the optical method to measure the volumetric strain [18-23]. The optical method involves photographing samples in a transparent high-pressure chamber using a high-precision digital camera. Indirect methods include calculations or measurements of parameters other than cola deformation. Siemons and Busch [24] and Romanov and Soong [25] studied the expansion of coal indirectly by measuring the change of free volume in a sample silo.

While previous studies have focused on swelling deformation characteristics of coal at the macro level, there is little understanding of internal swelling deformation at the micro level. Here, X-ray CT scanning technology was used to obtain a three-dimensional porous microstructure of coal in a nondestructive manner [26-28]. A combination of X-ray CT and 


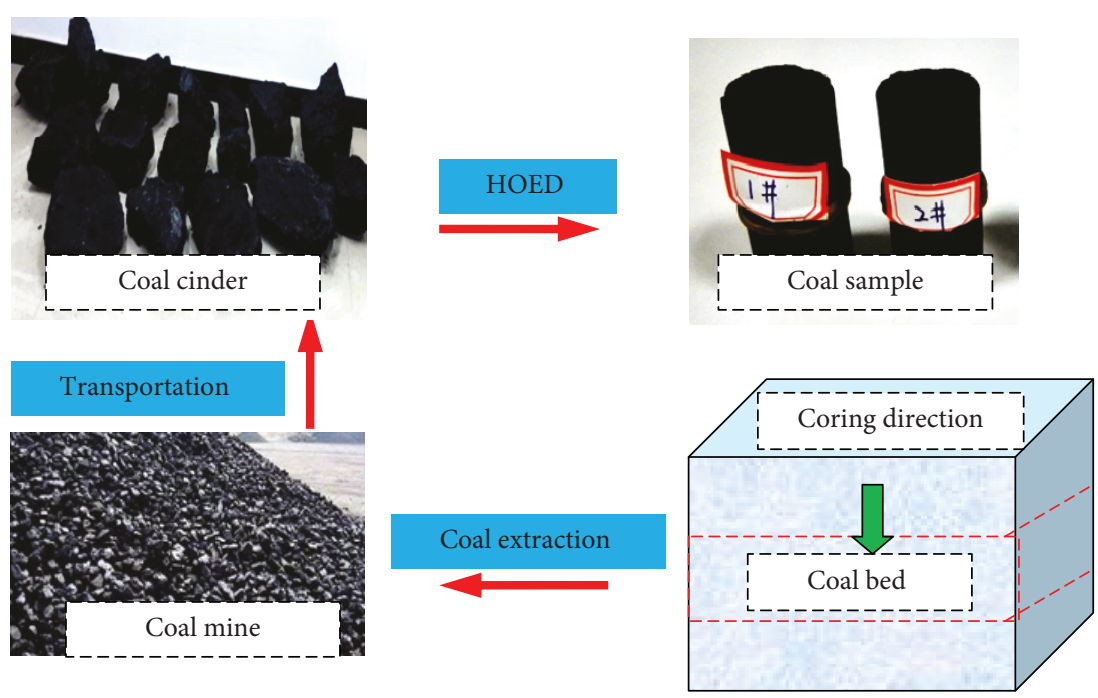

Figure 1: Schematic diagram of coal sample preparation.

special image analysis software was used to conduct coal swelling deformation tests. This offers a direct method for measuring swelling deformation, providing a better understanding of the mechanisms involved in coal deformation.

\section{Methods}

2.1. Materials. Coal samples for this study were from the Middle Jurassic Yan'an Formation in Ordos Basin, China. The maximum reflectance value of vitrinite is $0.43 \%$. The contents of vitrinite, inertinite, exinite, and minerals are $22.8 \%, 68.1 \%, 2.2 \%$, and $6.9 \%$, respectively. Core samples were collected using a hand-operated electric drill (HOED). The complete core preparation process is shown in Figure 1. It is important to note the relation between the cording direction and the coal bed. The top and the bottom of the coal samples were smoothed to achieve parallel surfaces. Coal samples had lengths of $50 \mathrm{~mm}$ and diameters of $25 \mathrm{~mm}$.

2.2. Experimental Apparatus. The experimental apparatus developed by the Shaanxi Key Laboratory of Advanced Stimulation Technology for Oil \& Gas Reservoirs, Xi'an Shiyou University, Xi'an, China, shown in Figure 2, consists mainly of the following devices. (1) The X-ray CT (Xradia 510 Versa; Zeiss, Germany) includes an X-ray source, a cavity, and a detector. The energy of the X-ray has a range of 30 to $160 \mathrm{kV}$ and can be adjusted until a high-resolution CT image is obtained. The cavity (Haian; $13.79 \mathrm{MPa}$; $150^{\circ} \mathrm{C}$ ) is a transparent container that is fixed on an adjustable turntable. The detector is capable of reaching to $2048 \times 2048$ pixels (unique spatial resolution of $<70 \mathrm{~nm}$ ). In this study, the X-ray source was set to $90 \mathrm{kV}$ with a resolution of $9.5 \mu \mathrm{m}$. (2) Stainless-steel cylinders $\left(0-70 \mathrm{MPa} ; 150^{\circ} \mathrm{C}\right.$; $1000 \mathrm{~mL}$; Huaan, China) were used as gas cells to store and deliver $\mathrm{CO}_{2}$. (3) A vacuum pump was used in the cavity to ensure that the results were not affected by other gases. (4) An injection pump (ISCO, flow range, 0.001-60 mL/min; flow accuracy, 0.5\%; pressure range, 0-68.96 $\mathrm{MPa}$; pressure accuracy, $0.1 \%$ ) was used to displace $\mathrm{CO}_{2}$. (5) A pressure sensor was used to monitor the pressure of the cavity. (6) The interface board is used to accept signals and pass signals to the computer.

2.3. Experimental Procedures. The swelling deformation of coal detected by X-ray CT was conducted using the following method.

(1) The system was set up as shown in Figure 2.

(2) High-purity $\mathrm{CO}_{2}$ was injected into the system to ensure it was properly sealed.

(3) The coal sample was mounted in the cavity. The vacuum pump was run for 24 hours to ensure no air remained in the system.

(4) The scan area and layer number was set up as in Figure 3. The central region of the core sample was used as the scanning area with a length of $24.80 \mathrm{~mm}$. In order to study the internal deformation of coal after adsorption of $\mathrm{CO}_{2}, 496$ scanning slices were designed in the scanning area. The distance between two slices was $0.05 \mathrm{~mm}$.

(5) The coal sample was then imaged by X-ray CT when the air in the system is exhausted.

(6) The $\mathrm{CO}_{2}$ was injected at a $0.1 \mathrm{~mL} / \mathrm{min}$ flow rate until the pressure of the cavity reached $0.5 \mathrm{MPa}$. To allow complete adsorption of the $\mathrm{CO}_{2}$, the coal sample was imaged by X-ray CT again at $24 \mathrm{~h}$ intervals [29].

(7) The $\mathrm{CO}_{2}$ was continuously injected into the cavity until the pressure of the cavity reached $1.0 \mathrm{MPa}$, 1.5 $\mathrm{MPa}$, 2.0 MPa, and 2.5 MPa. The sample was then imaged again as in step 5 . 


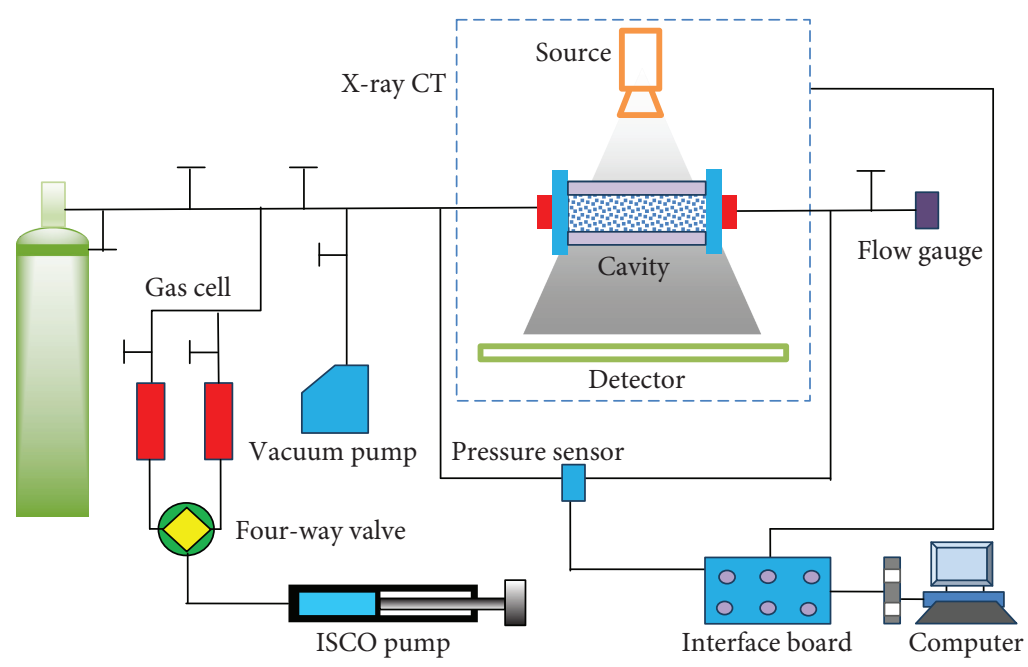

FIGURE 2: Schematic diagram of the experimental apparatus.

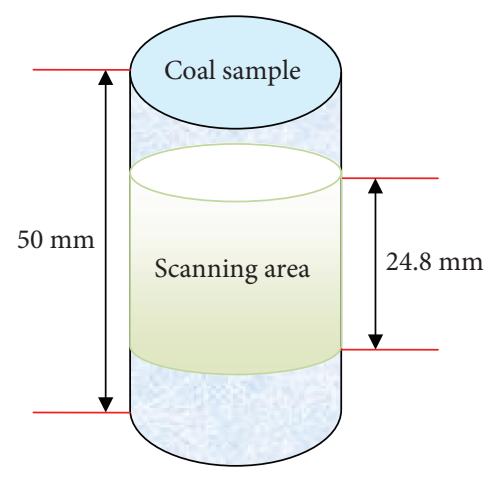

(a)

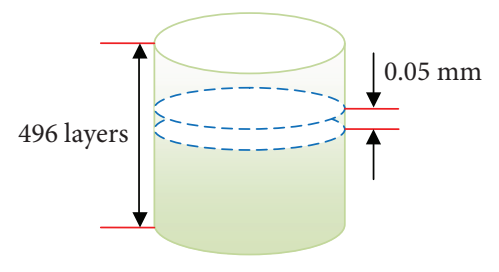

(b)

Figure 3: The scan design of the coal sample. (a) Scan area; (b) scan layers.

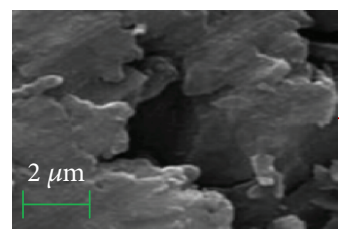

(a)

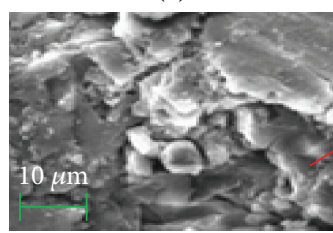

(b)

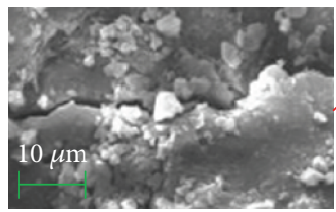

(c)

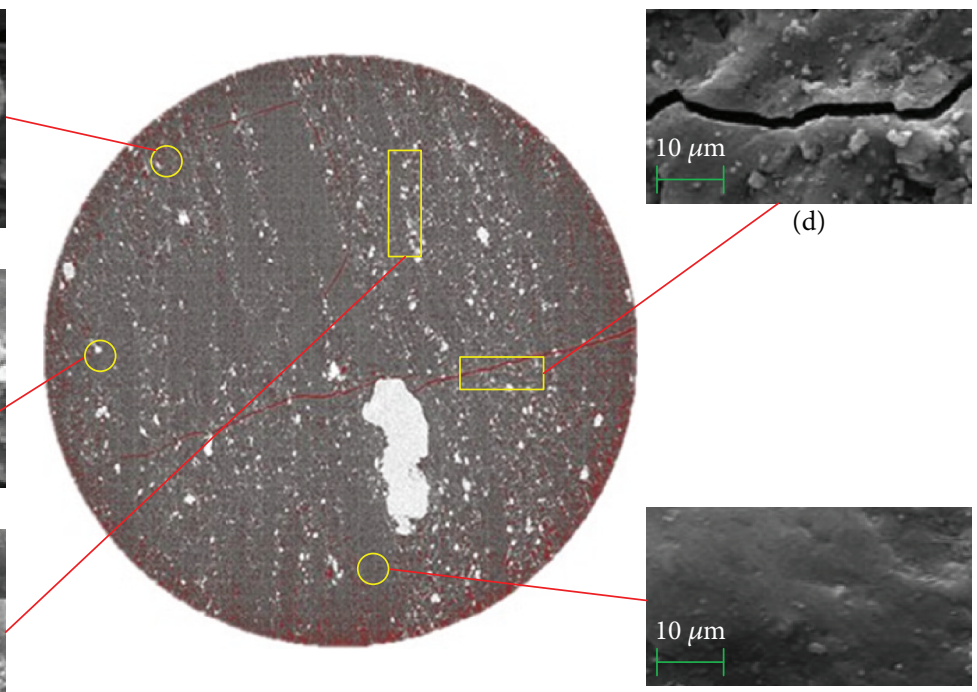

(e)

Figure 4: CT images and SEM images of coal in different regions. 


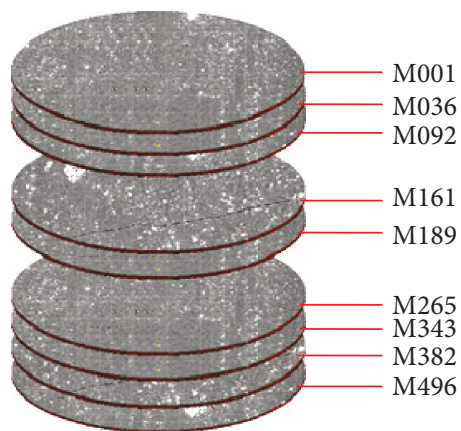

(a)

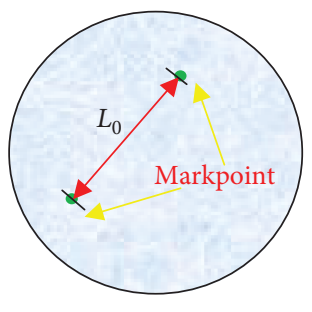

Before injection $\mathrm{CO}_{2}$

(c)

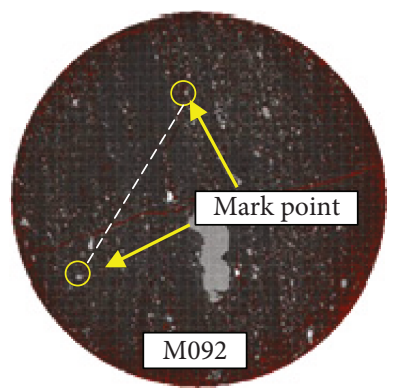

(b)

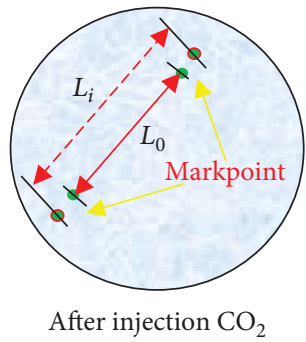

(d)

Figure 5: Schematic diagram of strain measurement.

TABLE 1: The strain of coal layer under different pressures.

\begin{tabular}{|c|c|c|c|c|c|c|c|c|c|c|}
\hline \multirow{2}{*}{ Pressure (MPa) } & \multicolumn{9}{|c|}{ Strain $\left(10^{-4}\right)$} & \multirow[b]{2}{*}{ Average } \\
\hline & M001 & M036 & M092 & M161 & M189 & M265 & M343 & M382 & M496 & \\
\hline 0.5 & 28.18 & 28.78 & 27.52 & 28.34 & 28.82 & 28.22 & 28.16 & 27.44 & 27.84 & 28.14 \\
\hline 1.0 & 43.06 & 42.16 & 43.19 & 43.43 & 42.71 & 42.31 & 43.52 & 42.71 & 41.99 & 42.75 \\
\hline 1.5 & 48.66 & 47.81 & 47.65 & 47.25 & 48.35 & 48.35 & 47.41 & 47.82 & 47.82 & 47.81 \\
\hline 2.0 & 53.12 & 52.14 & 51.87 & 53.28 & 52.83 & 52.52 & 53.07 & 52.81 & 53.17 & 52.71 \\
\hline 2.5 & 55.82 & 54.18 & 53.98 & 54.21 & 54.12 & 54.18 & 53.73 & 55.28 & 55.21 & 54.36 \\
\hline
\end{tabular}

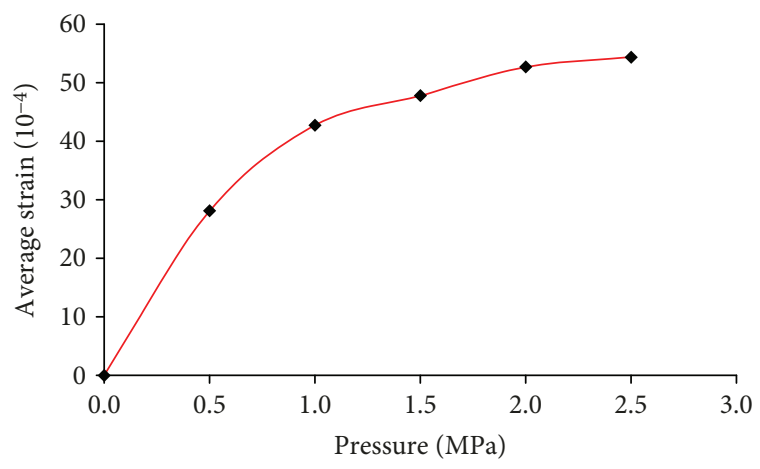

FIGURE 6: The average strain of the coal sample under different pressures.

\section{Results and Discussion}

3.1. Coal Structure. By comparing the SEM and tomographic images, the microstructure of coal can be observed clearly at the micron scale (Figure 4). The coal matrix is composed mainly of vitrinite, which contains a large number of micropores. Due to the layer structure and the distribution and

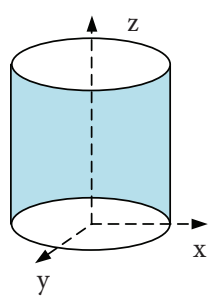

FIGURE 7: Fracture size measurement design.

density of the minerals, the microstructure of the coal is significantly deformed by $\mathrm{CO}_{2}$ adsorption. Figure 4 describes the coal structure, which can be divided into five regions (A-E) prior to deformation. (1) Region A is the matrix pore region. Image processing software colors the pores and fractures red. Clay minerals are crystallized in layers. There exist a large number of nanoscale pores with adsorption capacity in clay minerals. (2) Region B is the clay mineral cluster region. The CT scan showed multiple white clusters, indicating where the density was significantly greater than that of the coal matrix. (3) Region $\mathrm{C}$ is a fracture filled with clay minerals. This region has a white stripe in a certain direction in 


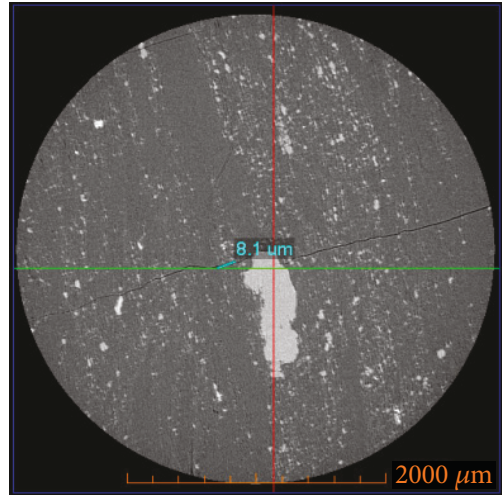

(a) $0 \mathrm{MPa}$

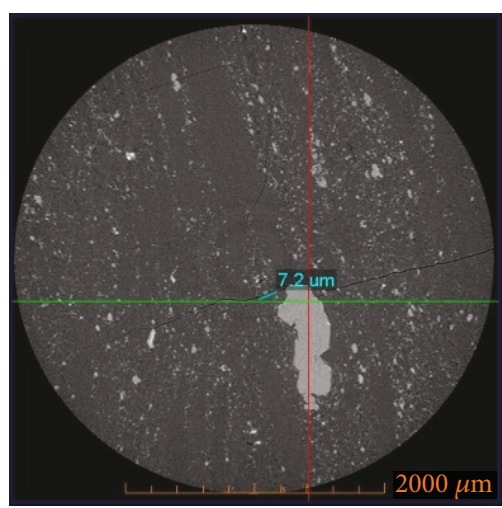

(d) $1.5 \mathrm{MPa}$

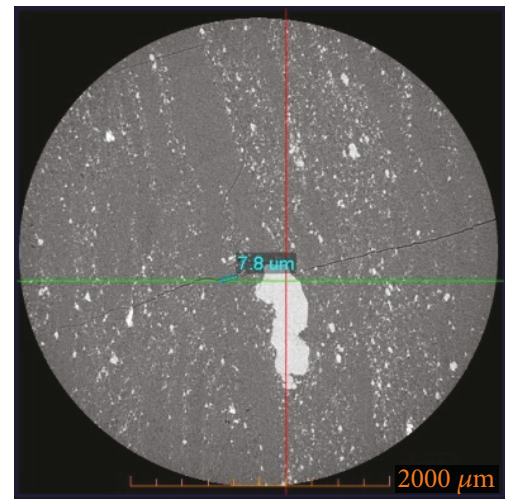

(b) $0.5 \mathrm{MPa}$

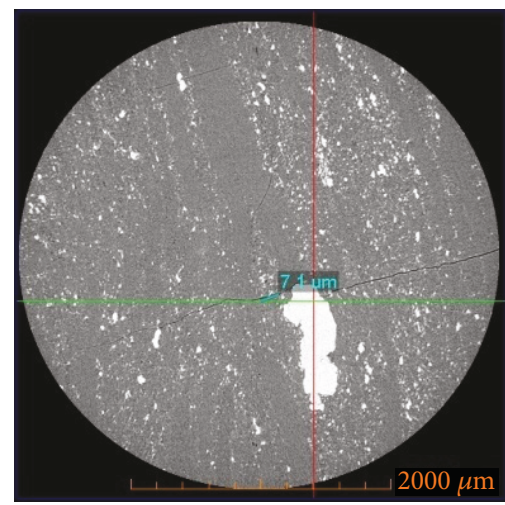

(e) $2.0 \mathrm{MPa}$

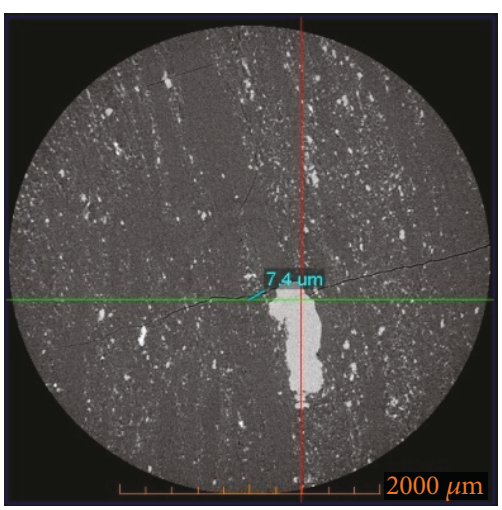

(c) $1.0 \mathrm{MPa}$

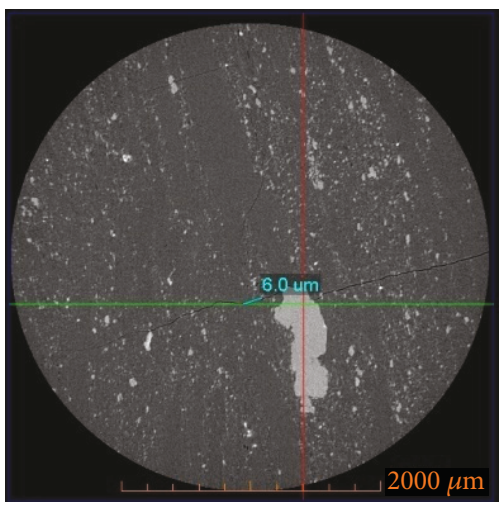

(f) $2.5 \mathrm{MPa}$

Figure 8: CT images of fracture size (xy section).

the CT image, with a length of several millimeters, and the density is significantly greater than the coal matrix. (4) Region $\mathrm{D}$ is the fracture region. A tension fracture provides a good channel for gas flowing. (5) Region $\mathrm{E}$ is the vitrinite region. The CT image of this region is uniform and dark. This region contains a large number of micropores. The density of this area is smaller than the density of Region B with good homogeneity.

\subsection{Quantifying Strain in Coal under Different Adsorption} Pressures. A novel method was designed to quantify the strain caused by the adsorption of $\mathrm{CO}_{2}$. As seen in Figure 5, nine layers were selected from the 496 layers available in the scan area (Figure 5(a)). CT scan results showed multiple white spots on the coal layer surface, which indicate impure minerals. In layer M092, for example (Figure 5(b)), two small but distinct clay mineral particles were used as markers. Object Research Systems (ORS) Visual 1.5.1 software was used to measure the distance between the two markers.

The distance $\left(L_{0}\right)$ between the two markers was measured (Figure 5(c)). $\mathrm{CO}_{2}$ was then injected into the cavity, and the change in distance caused by the deformation $\left(L_{i}\right)$ was measured (Figure $5(d)$ ). The strain $(\varepsilon)$ observed in the coal sample was obtained by

$$
\varepsilon=\frac{L_{i}-L_{0}}{L_{0}}
$$

Based on (1), the strain was calculated at different cavity pressures. As shown in Table 1, the strain observed in each layer varied under the same adsorption pressures. This is due to the variable composition of each layer and their differing abilities to adsorb $\mathrm{CO}_{2}$. The results indicate that the expansion deformation of each layer varies.

Previous studies showed that coal swells after $\mathrm{CO}_{2}$ adsorption [29]. We observed that at a microscopic scale, swelling occurs in a nonuniform manner. Depending on the composition of the layer, different levels of strain are observed, resulting in shear failure in the sample and a reduction in strength. Therefore, when studying the mechanical properties of coal influenced by $\mathrm{CO}_{2}$ adsorption, it is recommended that the deformation be considered at a microscopic scale.

In order to quantify the relationship between the adsorption pressure and strain, the mean value of strain for the nine layers was calculated. The relationship between the adsorption pressure and strain is shown in Figure 6. The adsorption capacity of coal increased with adsorption pressure, leading to expansion. As the pressure rises and the coal reaches its adsorption capacity, the strain stabilizes.

3.3. Fracture Size under Different Adsorption Pressures. The fracture volume of coal is compressed due to the swelling deformation of the matrix after adsorption of $\mathrm{CO}_{2}$, which was obtained through speculation in previous studies. CT 


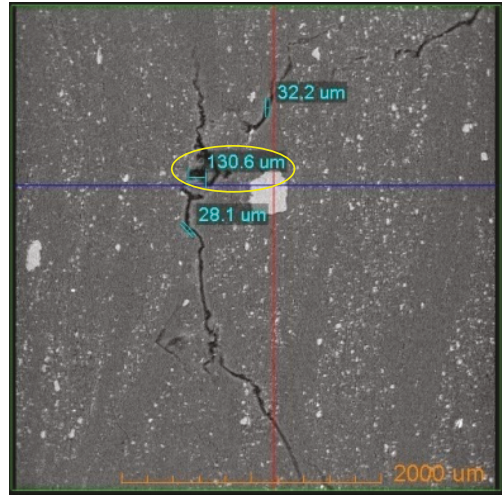

(a) $0 \mathrm{MPa}$

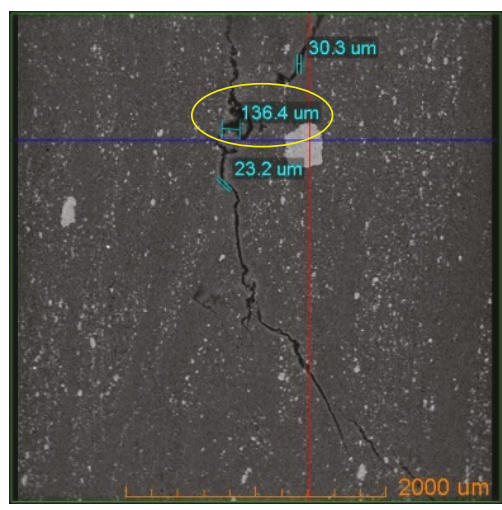

(d) $1.5 \mathrm{MPa}$

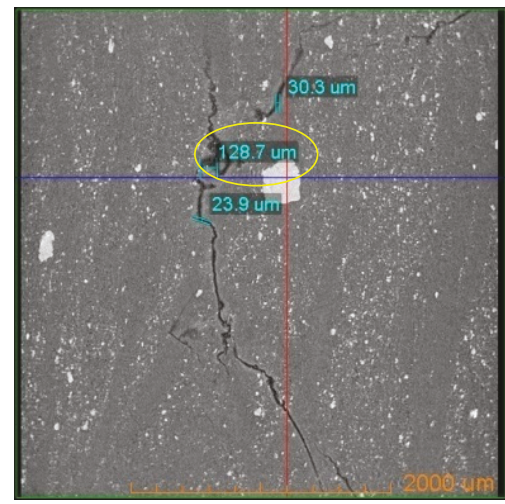

(b) $0.5 \mathrm{MPa}$

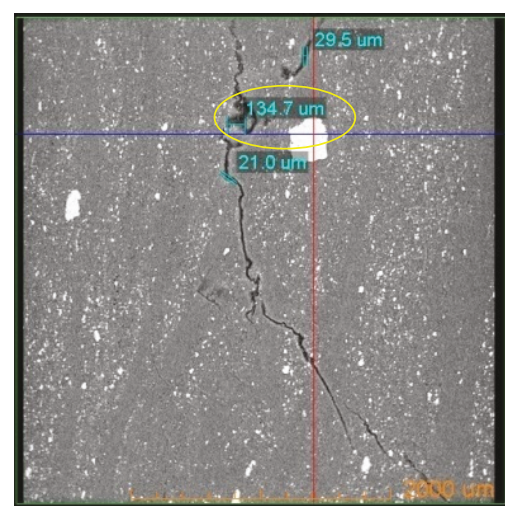

(e) $2.0 \mathrm{MPa}$

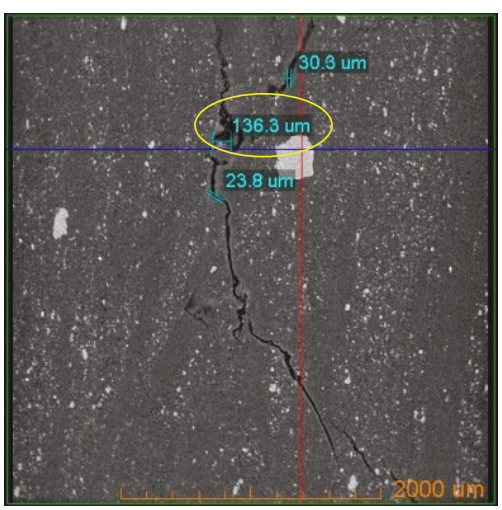

(c) $1.0 \mathrm{MPa}$

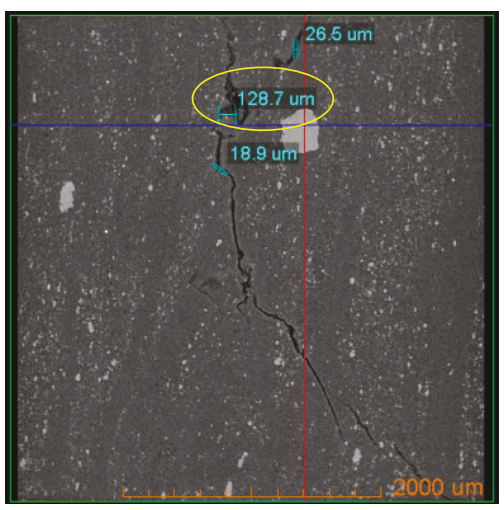

(f) $2.5 \mathrm{MPa}$

Figure 9: CT images of fracture size (xz section).

scan experiments were designed in order to clearly observe the development of fractures due to $\mathrm{CO}_{2}$ adsorption. As shown in Figure 7, this method records the geometrical dimensions of the fractures in the $x y, y z$, and $x z$ sections under different adsorption pressures. The size of the fracture in the same position was measured continuously under different adsorption pressures. The experimental results are shown in Figures 8-10.

With the exception of a single point in Figures 8-10, the size of the fracture decreased with increasing adsorption pressure. Coal is a complex porous medium composed of a matrix and fracture space of cutting coal matrix. The coal matrix is linked by the rock bride. There is a large amount of pore space in the coal matrix, which provides sufficient places for coal to absorb $\mathrm{CO}_{2}$. The expansion and deformation of the coal matrix resulting from $\mathrm{CO}_{2}$ adsorption affect the volume of the fracture in the coal, as shown in Figure 11. Figure 9 shows a complex fracture (marked by a yellow circle) that produced an uneven deformation as a result of local shear stress. The general trend, however, is that fracture size decreases with increasing adsorption pressure.

In order to more clearly display the development of fractures, ORS Visual software was used to digitize the scanning coal samples. As shown in Figure 12, the matrix of the coal sample is stripped off, and only the fracture is retained.

In order to compare and analyze the characteristics of fracture size under different adsorption pressures, the fracture is processed with pseudocolor processing. The results of processing are shown in Figure 13. The color scale changes from blue to red, indicating that the fracture size increases gradually. As the adsorption pressure increases, the fracture color gradually changes from dark to light green, indicating that the fracture is closed gradually. This is due to the expansion caused by $\mathrm{CO}_{2}$ adsorption, which leads to compression in some regions. The red line in Figure 13 shows that as adsorption pressure increases, the fracture gradually disappears.

3.4. Porosity of Coal under Different Adsorption Pressures. Quantifying the porosity of coal can be used to evaluate carbon sequestration capacity. Mercury injection is useful to measure the initial porosity; however, it is not appropriate to use after $\mathrm{CO}_{2}$ adsorption. CT scanning technology is not only capable to measuring porosity under different adsorption pressures but can also accurately measuring porosity under different adsorption pressures but can also accurately measure the change in pore microstructure after $\mathrm{CO}_{2}$ adsorption. The porosity of the coal sample was $31.36 \%$ without $\mathrm{CO}_{2}$ adsorption, which was obtained through the NMR (MiniMR-HTHP; Zeiss, Germany) method [30, 31]. To calculate the porosity under different adsorption pressures, CT images need to be treated with binarization. The key parameter of binarization processing is the selection of the binarization threshold. To obtain an accurate binarization threshold, a CT scan of the coal sample was performed 


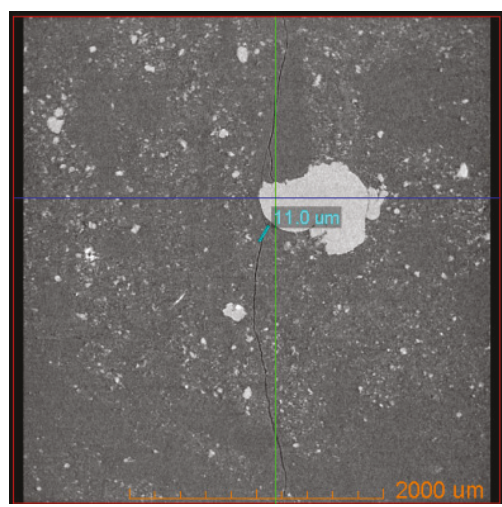

(a) $0 \mathrm{MPa}$

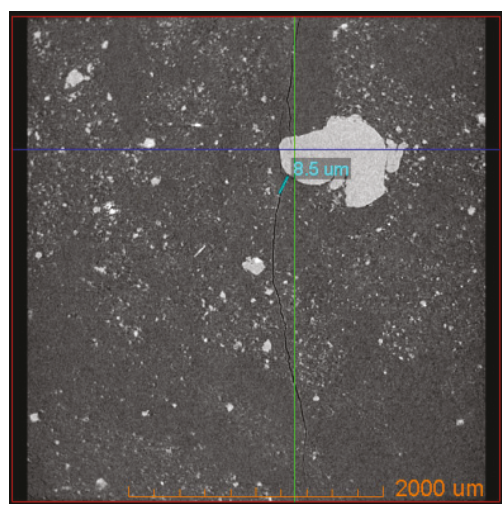

(d) $1.5 \mathrm{MPa}$

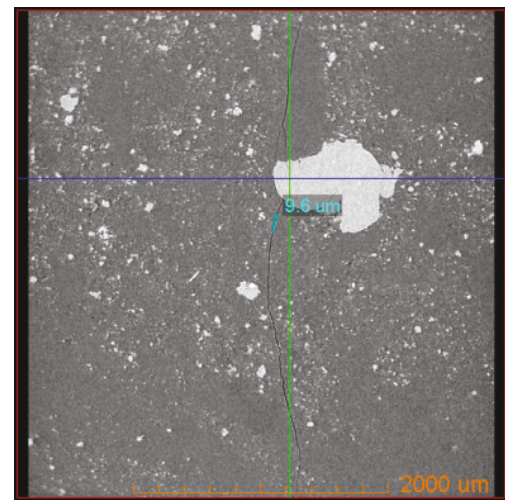

(b) $0.5 \mathrm{MPa}$

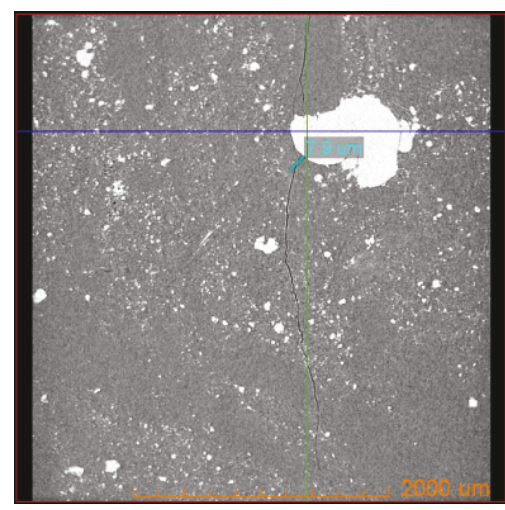

(e) $2.0 \mathrm{MPa}$

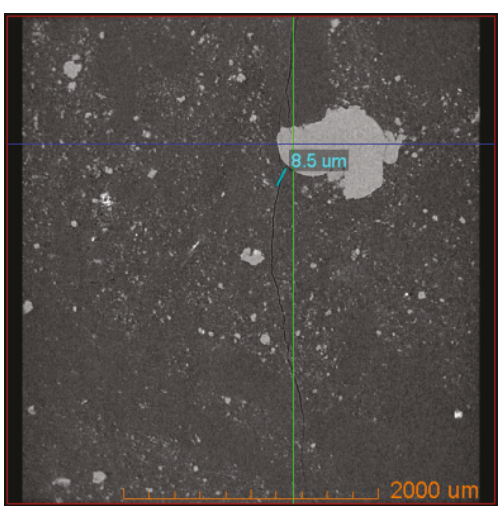

(c) $1.0 \mathrm{MPa}$

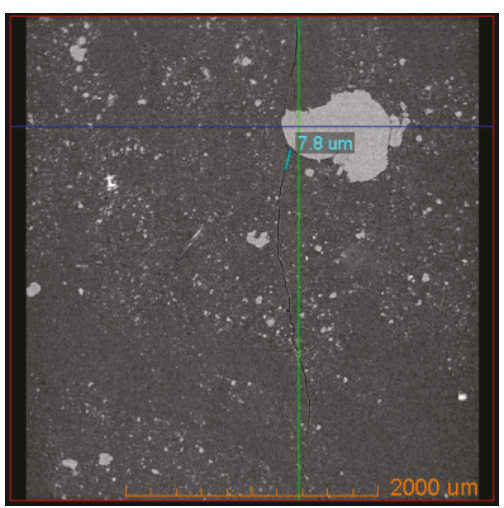

(f) $2.5 \mathrm{MPa}$

FIGURE 10: CT images of fracture size (yz section).

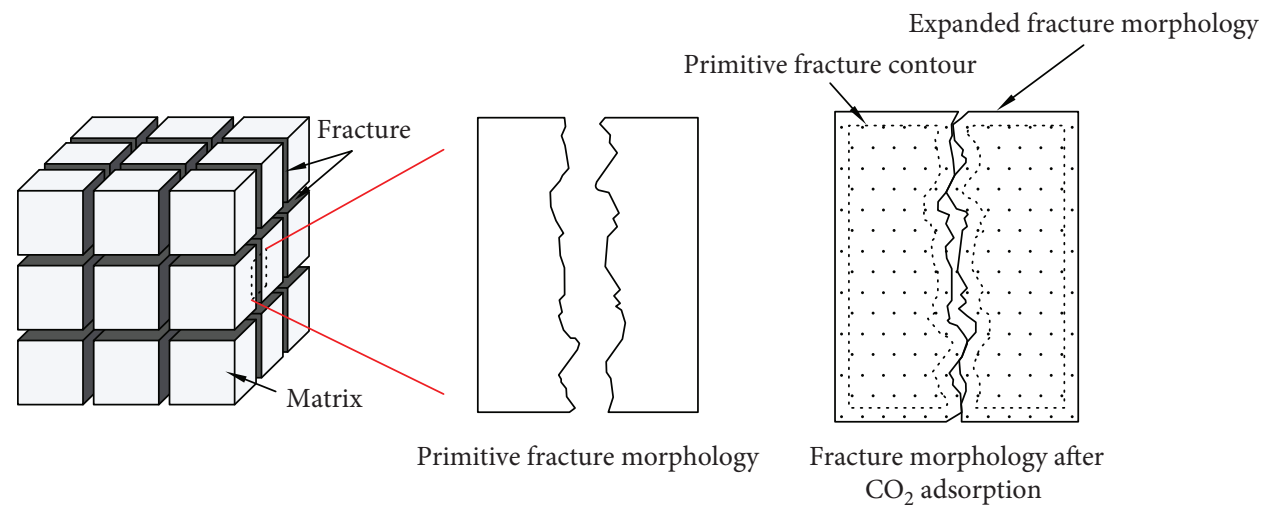

FIgURE 11: Expansion deformation of coal after adsorbing $\mathrm{CO}_{2}$.

to obtain the grayscale. The grayscale image was ten treated by binarization processing at different thresholds, and the porosity under different thresholds was calculated. The results showed that the porosity of coal was $31.36 \%$, which was the same value obtained via the NMR method when the threshold value was 0.006 . Therefore, the binarization threshold is set to 0.006 for gray image processing under different adsorption pressures. Calculated results of porosity under different adsorption pressures are shown in Figure 14. As adsorption pressure increased, porosity decreased.
Figure 15 shows the mechanism of porosity reduction. The coal can be described by the dual medium of matrix and fracture. Once $\mathrm{CO}_{2}$ is injected into the core sample, it begins to enter the fracture through laminar flow. After a period of time, $\mathrm{CO}_{2}$ begins to diffuse into the small pores in the matrix. $\mathrm{CO}_{2}$ is transported to the coal matrix and gradually adsorbed onto the surface. $\mathrm{CO}_{2}$ adsorption on the microporous surface of coal matrix induced swelling of the matrix, which then compresses the fractures and pores. At the same time, the swelling of the coal matrix increases the volume of the coal, which affects the porosity. 


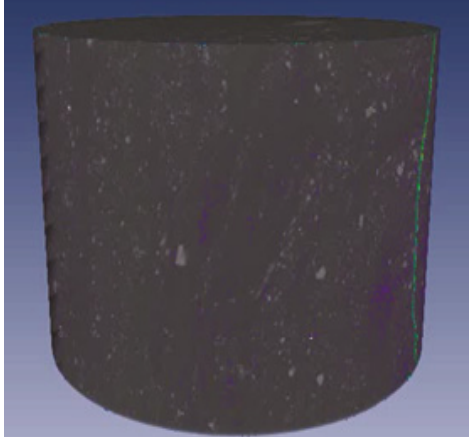

Matrix and fracture

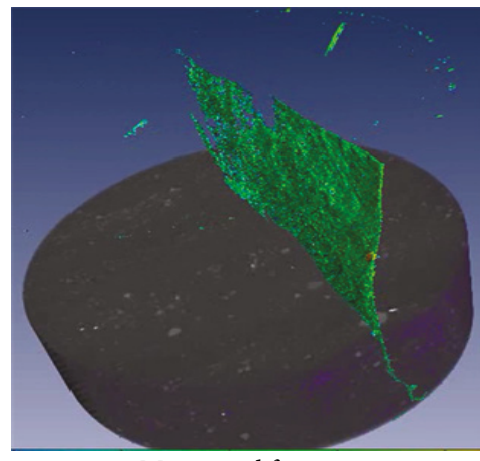

Matrix and fracture

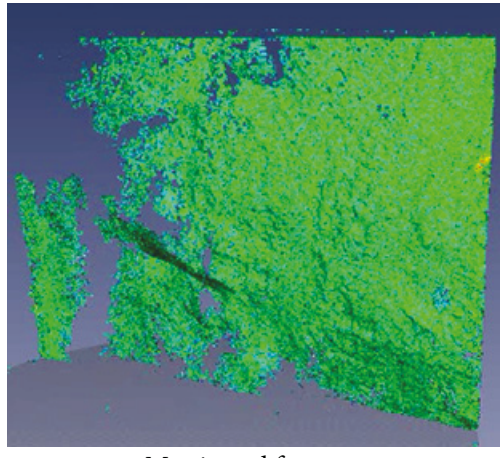

Matrix and fracture

FIGURE 12: Fracture extraction in CT image.

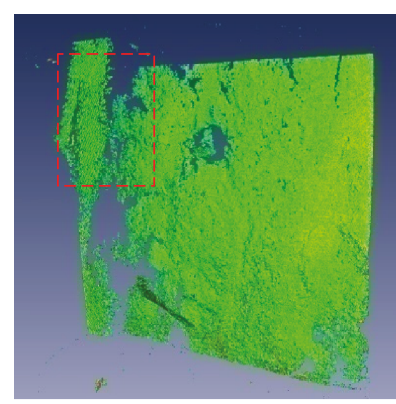

(a) $0 \mathrm{MPa}$

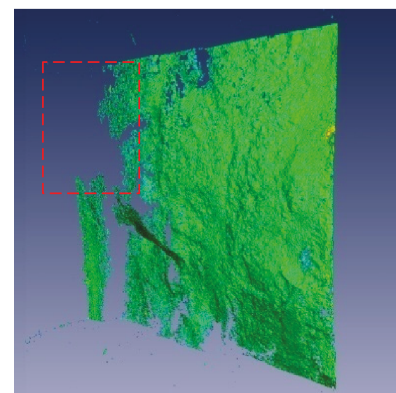

(d) $1.5 \mathrm{MPa}$

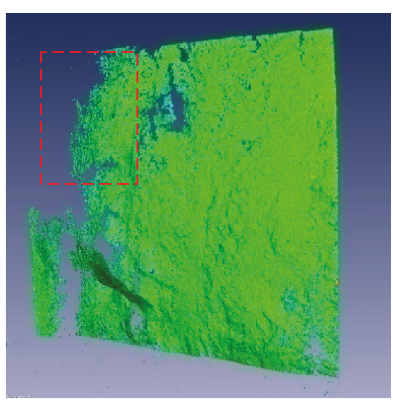

(b) $0.5 \mathrm{MPa}$

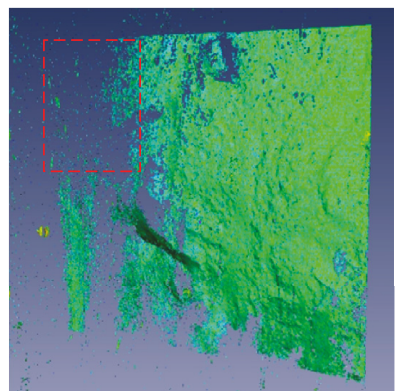

(e) $2.0 \mathrm{MPa}$

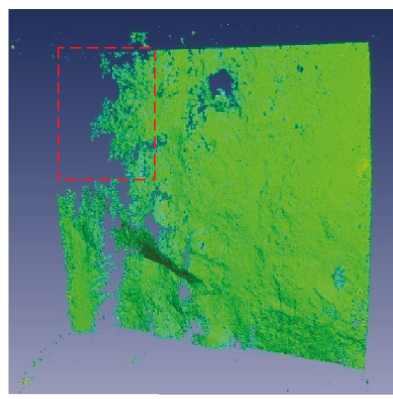

(c) $1.0 \mathrm{MPa}$

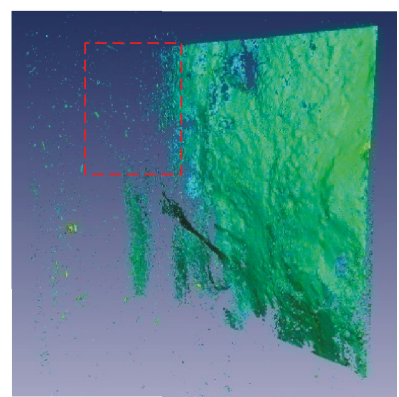

(f) $2.5 \mathrm{MPa}$

Thickness (Micrometers)

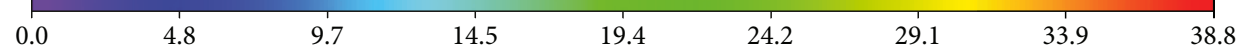

FIGURE 13: Characteristics of fracture evolution based on CT pseudocolor images.

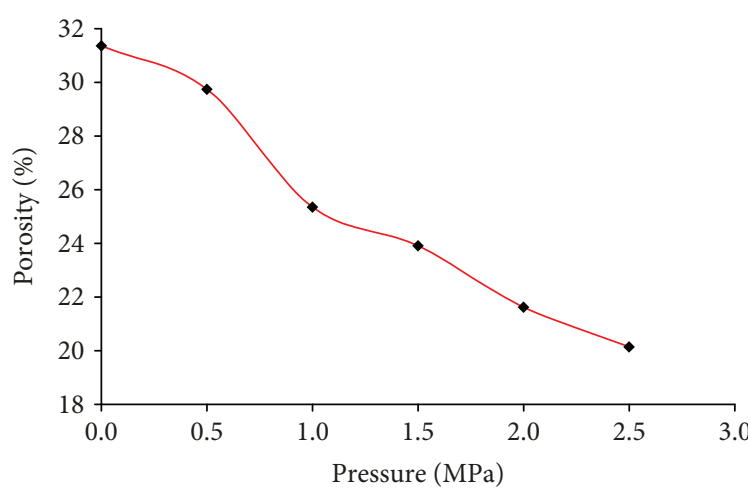

Figure 14: Porosity change of coal samples under different pressures.
3.5. Coal Density under Different Adsorption Pressures. The extrusion deformation and swelling deformation of the internal structure of the coal cause changes in density. So the microscopic deformation is reflected in the change of coal density. From the CT imaging principle, the X-ray attenuation coefficient increases with the increase of the density of the monitored object. As the attenuation coefficient increases, the color of the CT image lightens. CT images under different adsorption pressures are shown in Figure 16. The images show that the composition of the coal is extremely nonuniform. Generally, coal density increased with increasing adsorption pressure, resulting from a nonuniform extrusion.

The coal density increases with adsorption pressure increasing. The main reason for the increase of coal density is the nonuniform extrusion deformation of coal internal. 


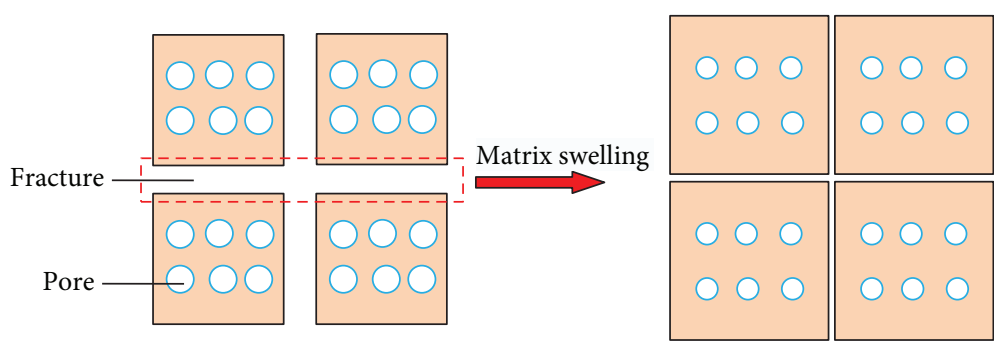

FIGURE 15: Schematic diagram of porosity reduction.
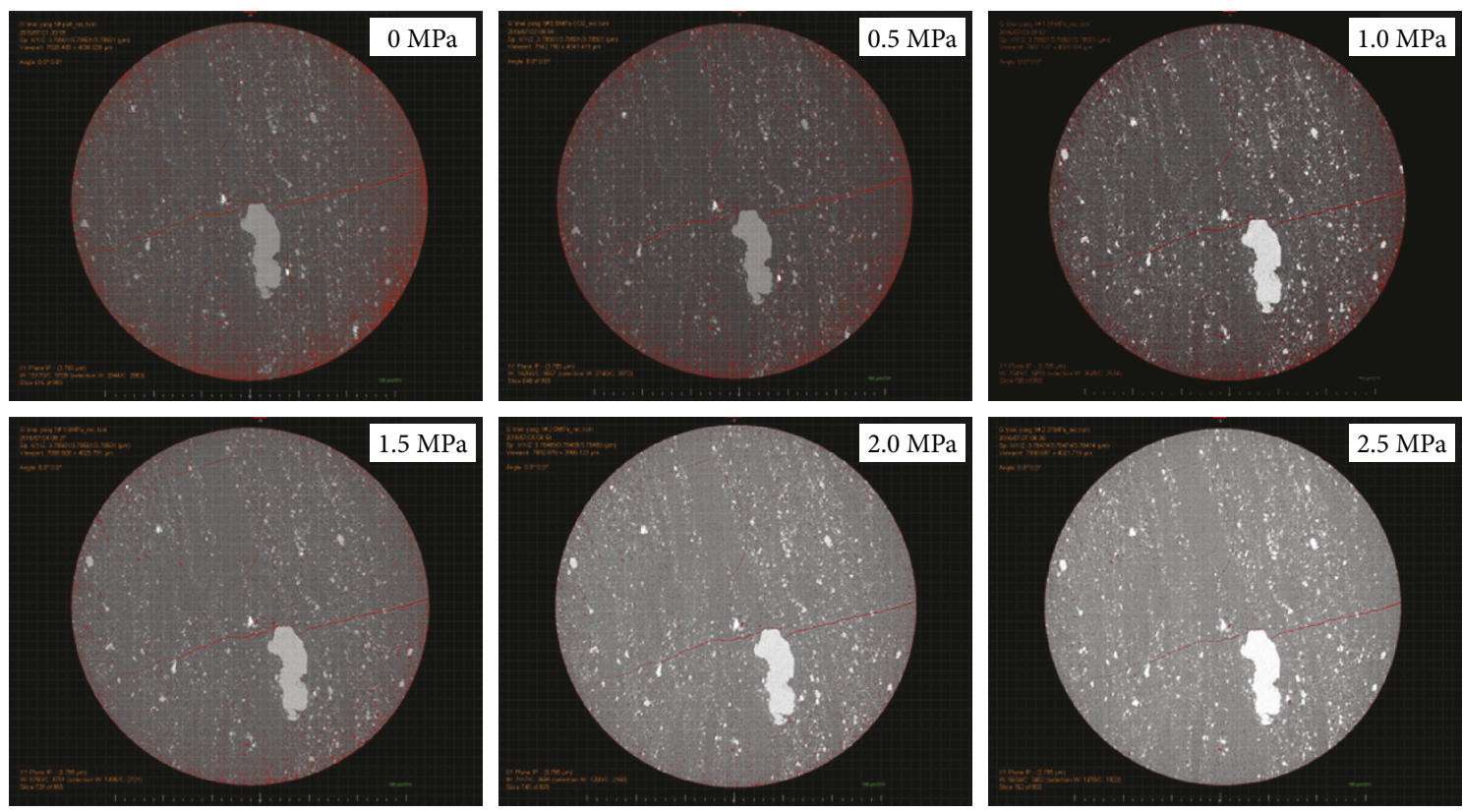

FIGURE 16: CT images of coal under different adsorption pressures.

The main reason for the decrease of coal density is the expansion deformation of coal internal. It can be clearly seen from Figure 16 that the coal density generally increases with the increase of adsorption pressure, which is because the leading role is extrusion deformation.

\section{Conclusion}

$\mathrm{CO}_{2}$ injected into the coal bed causes matrix swelling, which severely limits the $\mathrm{CO}_{2}$ 's storage potential. Previous studies have hypothesized that matrix expansion leads to porosity and fracture closure, resulting in a decrease in porosity. However, this assumption has not been directly observed. Here, $\mathrm{X}$-ray CT was used to directly observe the internal variation in the characteristics of coal caused by $\mathrm{CO}_{2}$ adsorption. The main conclusions drawn in this study are as follows.

(1) Coal is heterogeneous, containing a small amount of clay minerals. This was observed through a combination of CT scanning grayscale images and SEM images. The structure of the coal can be divided into five regions: the matrix pore region, the clay mineral cluster region, the fracture filled with clay mineral region, the fracture region, and the vitrinite region.
(2) Internal swelling deformation at different positions was studied quantitatively using X-ray CT scans, which revealed a high heterogeneity. Furthermore, this nonuniform swelling changes the stress state of the coal, reducing its mechanical strength.

(3) Swelling increases with increased adsorption pressure, leading to the gradual closure of fractures.

(4) Swelling of the coal matrix is due to $\mathrm{CO}_{2}$ absorption, which compresses the volume of pores and fractures. At the same time, the matrix swelling increases the sample volume. These factors contribute to the decreasing porosity of the coal sample.

(5) Grayscale images obtained via X-ray CT directly reflect the internal changes of coal after $\mathrm{CO}_{2}$ adsorption. The density of the coal sample increased as the sample adsorbed $\mathrm{CO}_{2}$.

\section{Data Availability}

The data used to support the findings of this study are available from the corresponding author upon request. 


\section{Conflicts of Interest}

The authors declare no conflict of interest.

\section{Acknowledgments}

This paper is supported by the National Natural Science Foundation of China (Program no. 51674197), Science and Technology Research Development Plan Project of Shaanxi Province, China, (Program no. 2016GY-162), and Natural Science Basic Research Plan in Shaanxi Province of China (Program no. 2018JQ4033). The authors would like to express their appreciation to the other members of the laboratory for the help provided in the experiments and language editing.

\section{References}

[1] T. Kempka, B. Norden, A. Ivanova, and S. Lüth, "Revising the static geological reservoir model of the Upper Triassic Stuttgart Formation at the Ketzin pilot site for $\mathrm{CO}_{2}$ storage by integrated inverse modelling," Energies, vol. 10, no. 10, p. 1559, 2017.

[2] R. Chen, Y. Qin, C. Wei, L. Wang, Y. Wang, and P. Zhang, "Changes in pore structure of coal associated with $\mathrm{Sc}-\mathrm{CO}_{2}$ extraction during $\mathrm{CO}_{2}$-ECBM," Applied Sciences, vol. 7, no. 9 , p. 931, 2017.

[3] G. Yin, B. Deng, M. Li et al., "Impact of injection pressure on $\mathrm{CO}_{2}$-enhanced coalbed methane recovery considering mass transfer between coal fracture and matrix," Fuel, vol. 196, pp. 288-297, 2017.

[4] C. O. Karacan, "Heterogeneous sorption and swelling in a confined and stressed coal during $\mathrm{CO}_{2}$ injection," Energy \& Fuels, vol. 17, no. 6, pp. 1595-1608, 2003.

[5] X. Ji, D. Song, X. Ni, Y. Li, and H. Zhao, "Coal matrix deformation and pore structure change in high-pressure nitrogen replacement of methane," Energies, vol. 11, no. 1, p. 175, 2018.

[6] A. Busch, Y. Gensterblum, B. M. Krooss, and R. Littke, "Methane and carbon dioxide adsorption-diffusion experiments on coal: upscaling and modeling," International Journal of Coal Geology, vol. 60, no. 2-4, pp. 151-168, 2004.

[7] H. Briggs and R. P. Sinha, "V.-Expansion and contraction of coal caused respectively by the sorption and discharge of gas," Proceedings of the Royal Society of Edinburgh, vol. 53, pp. 4853, 1934.

[8] P. J. Reucroft and H. Patel, "Gas-induced swelling in coal," Fuel, vol. 65, no. 6, pp. 816-820, 1986.

[9] P. J. Reucroft and A. R. Sethuraman, "Effect of pressure on carbon dioxide induced coal swelling," Energy \& Fuels, vol. 1, no. 1, pp. 72-75, 1987.

[10] P. L. Walker Jr., S. K. Verma, J. Rivera-Utrilla, and M. R. Khan, "A direct measurement of expansion in coals and macerais induced by carbon dioxide and methanol," Fuel, vol. 67, no. 5, pp. 719-726, 1988.

[11] D. H. Moffat and K. E. Weale, "Sorption by coal of methane at high pressure," Fuel, vol. 34, pp. 449-462, 1955.

[12] S. Harpalani and R. Schraufnagel, "Shrinkage of coal matrix with release of gas and its impact on permeability of coal," Fuel, vol. 69, no. 5, pp. 551-556, 1990.
[13] J. R. Levine, "Model study of the influence of matrix shrinkage on absolute permeability of coal bed reservoirs," Geological Society, London, Special Publications, vol. 109, no. 1, pp. 197212, 1996

[14] J. D. St. George and M. A. Barakat, "The change in effective stress associated with shrinkage from gas desorption in coal," International Journal of Coal Geology, vol. 45, no. 2-3, pp. 105-113, 2001.

[15] X. Cui, R. M. Bustin, and L. Chikatamarla, "Adsorptioninduced coal swelling and stress: implications for methane production and acid gas sequestration into coal seams," Journal of Geophysical Research, vol. 112, no. B10, 2007.

[16] Z. Majewska and J. Zietek, "Changes of acoustic emission and strain in hard coal during gas sorption-desorption cycles," International Journal of Coal Geology, vol. 70, no. 4, pp. 305312, 2007.

[17] K. Zarebska and G. Ceglarska-Stefanska, "The change in effective stress associated with swelling during carbon dioxide sequestration on natural gas recovery," International Journal of Coal Geology, vol. 74, no. 3-4, pp. 167-174, 2008.

[18] E. P. Robertson and R. L. Christiansen, "Measurement of sorption-induced strain," in Proceeding of the 2005 International Coalbed Methane Symposium, pp. 1-15, Tuscaloosa, Alabama, 2005

[19] S. Day, R. Fry, and R. Sakurovs, "Swelling of Australian coals in supercritical $\mathrm{CO}_{2}$," International Journal of Coal Geology, vol. 74, no. 1, pp. 41-52, 2008.

[20] S. Ottiger, R. Pini, G. Storti, and M. Mazzotti, "Competitive adsorption equilibria of $\mathrm{CO}_{2}$ and $\mathrm{CH}_{4}$ on a dry coal," Adsorption, vol. 14, no. 4-5, pp. 539-556, 2008.

[21] R. Pini, S. Ottiger, L. Burlini, G. Storti, and M. Mazzotti, " $\mathrm{CO}_{2}$ storage through ECBM recovery: an experimental and modeling study," Energy Procedia, vol. 1, no. 1, pp. 1711-1717, 2009.

[22] F. Van Bergen, C. Spiers, G. Floor, and P. Bots, "Strain development in unconfined coals exposed to $\mathrm{CO}_{2}, \mathrm{CH}_{4}$ and $\mathrm{Ar}$ : effect of moisture," International Journal of Coal Geology, vol. 77, no. 1-2, pp. 43-53, 2009.

[23] S. Durucan, M. Ahsanb, and J. Q. Shia, "Matrix shrinkage and swelling characteristics of European coals," Energy Procedia, vol. 1, no. 1, pp. 3055-3062, 2009.

[24] N. Siemons and A. Busch, "Measurement and interpretation of supercritical $\mathrm{CO}_{2}$ sorption on various coals," International Journal of Coal Geology, vol. 69, no. 4, pp. 229-242, 2007.

[25] V. Romanov and Y. Soong, "Long-term $\mathrm{CO}_{2}$ sorption on upper freeport coal powder and lumps," Energy \& Fuels, vol. 22, no. 2, pp. 1167-1169, 2008.

[26] L. M. Pant, H. Huang, M. Secanell, S. Larter, and S. K. Mitra, "Multi scale characterization of coal structure for mass transport,” Fuel, vol. 159, pp. 315-323, 2015.

[27] Z. Feng, D. Zhou, Y. Zhao, and T. Cai, "Study on microstructural changes of coal after methane adsorption," Journal of Natural Gas Science and Engineering, vol. 30, pp. 28-37, 2016.

[28] X. Zhang, K. Wang, A. Wang, and P. Gong, "Analysis of internal pore structure of coal by micro-computed tomography and mercury injection," International Journal of Oil, Gas and Coal Technology, vol. 12, no. 1, pp. 38-50, 2016.

[29] Y. Zhang, M. Lebedev, M. Sarmadivaleh, A. Barifcani, and S. Iglauer, "Swelling-induced changes in coal microstructure due to supercritical $\mathrm{CO}_{2}$ injection," Geophysical Research Letters, vol. 43, no. 17, pp. 9077-9083, 2016. 
[30] J. P. Yan, X. He, B. Geng et al., "Nuclear magnetic resonance $T_{2}$ spectrum: multifractal characteristics and pore structure evaluation," Applied Geophysics, vol. 14, no. 2, pp. 205-215, 2017.

[31] Y. Yao, D. Liu, Y. Che, D. Tang, S. Tang, and W. Huang, "Petrophysical characterization of coals by low-field nuclear magnetic resonance (NMR)," Fuel, vol. 89, no. 7, pp. 13711380, 2010. 

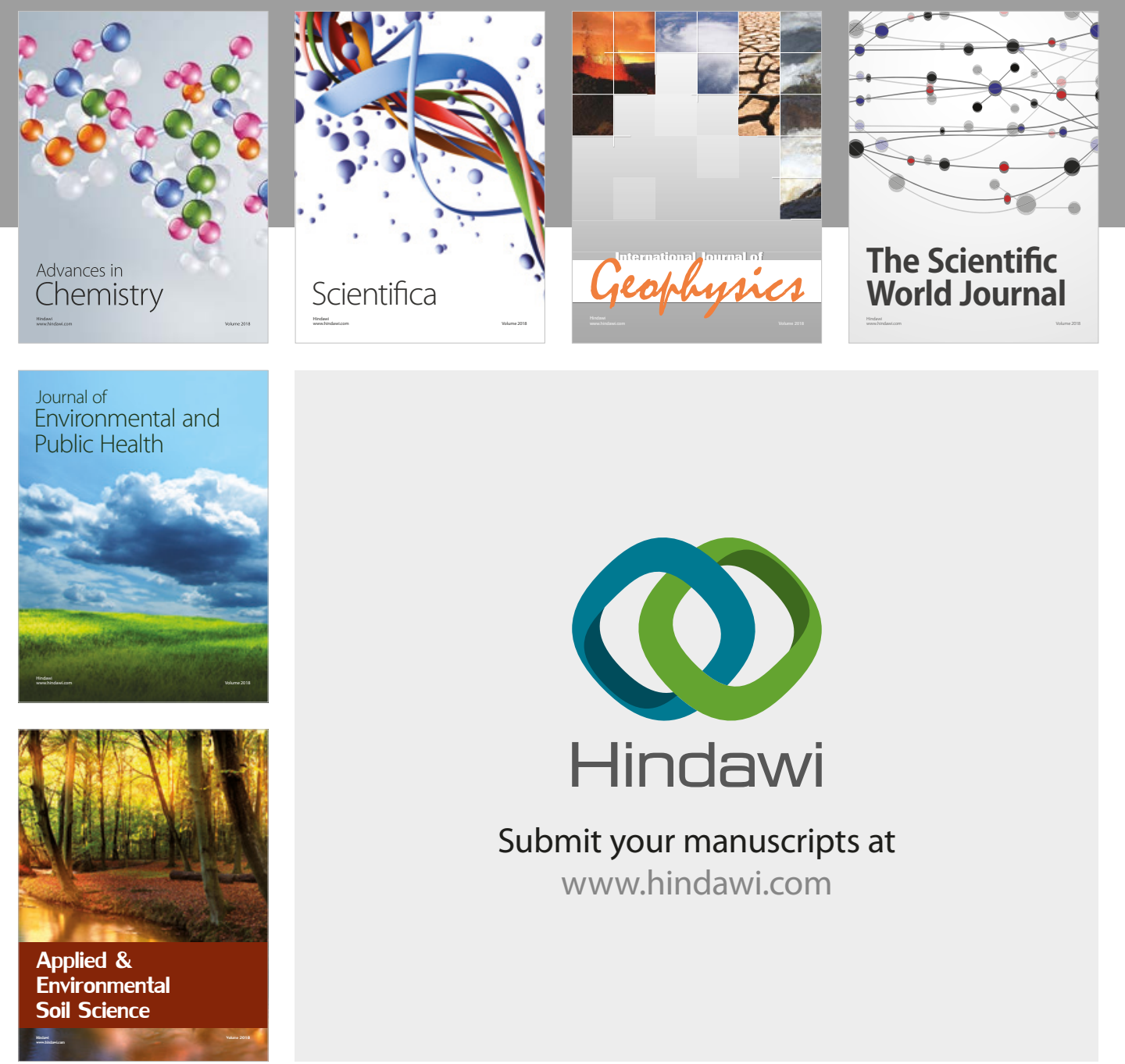

The Scientific

\section{World Journal}
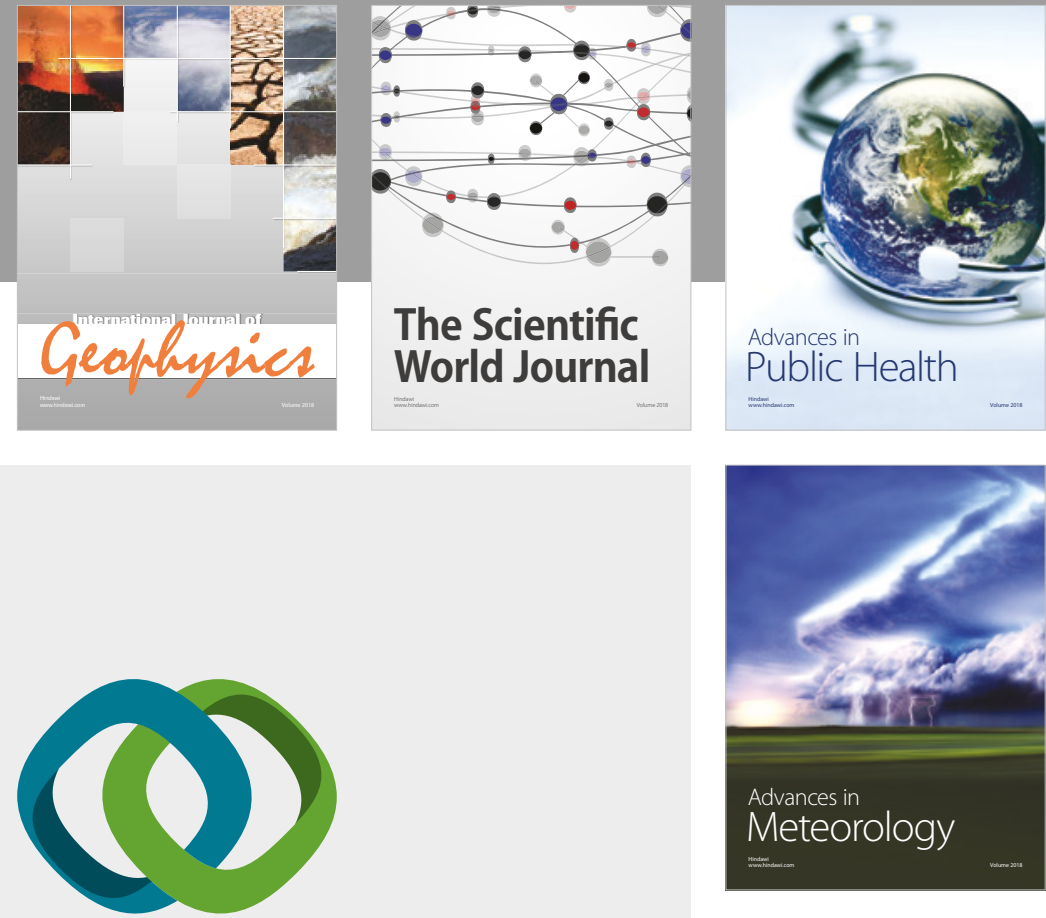

Advan

Public Health

\section{Hindawi}

Submit your manuscripts at

www.hindawi.com
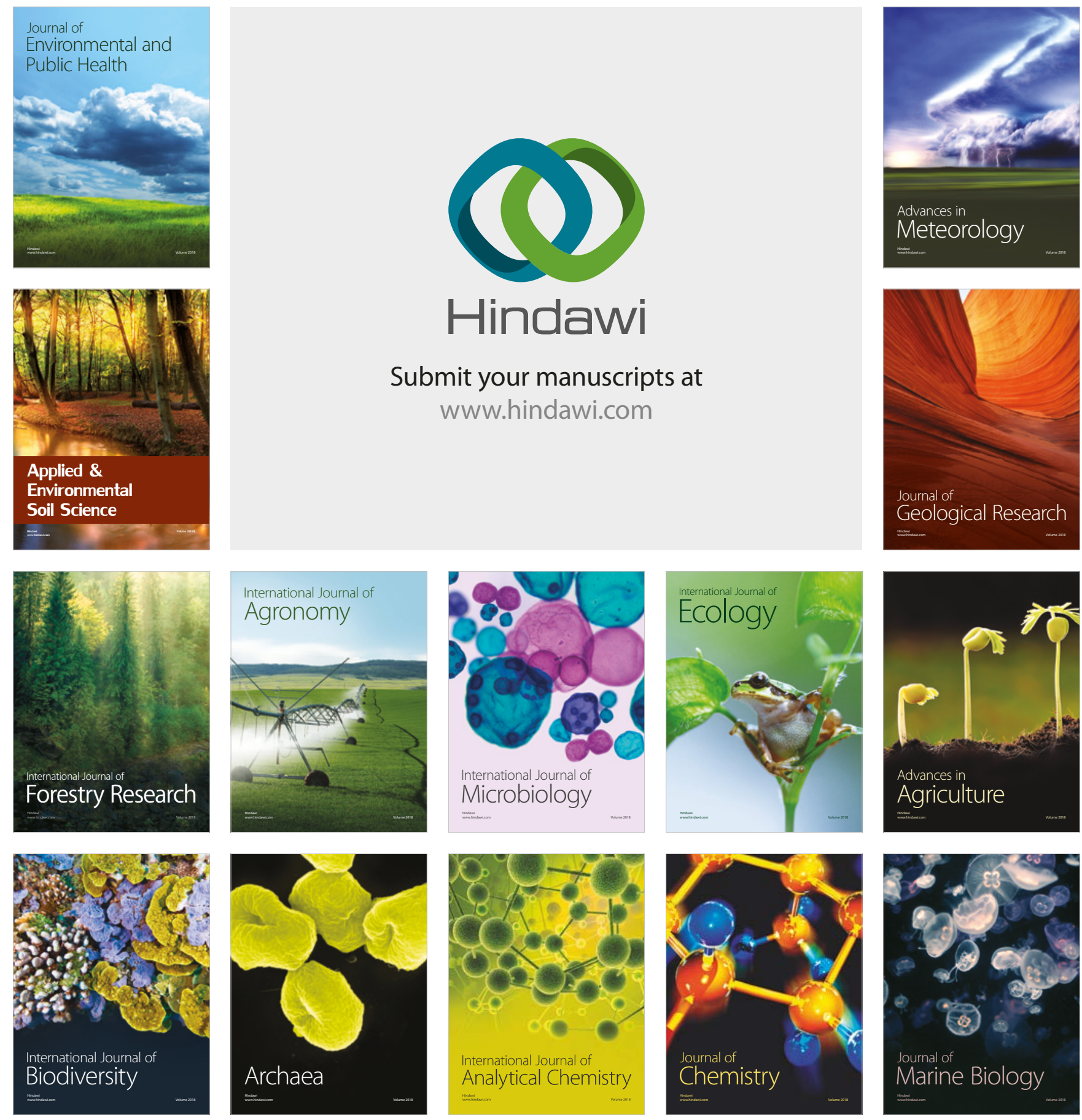